\title{
The Expression of Markers Related to Ovarian Germline Stem Cells in the Mouse Ovarian Surface Epithelium and the Correlation with Notch Signaling Pathway
}

\author{
Zezheng Pan ${ }^{a, b}$ Mengli Sun ${ }^{a, c}$ Jia Lia Fangyue Zhou ${ }^{a}$ Xia Liang ${ }^{a}$ Jian Huang ${ }^{a}$ \\ Tuochen Zheng $^{d}$ Liping Zheng ${ }^{\text {a }}$ Yuehui Zheng ${ }^{\text {a }}$
}

a Medical Teaching Laboratory Center, Jiangxi Medical College, Nanchang University, Nanchang, bFaculty of Basic Medical Science, Jiangxi Medical College, Nanchang University, Nanchang, 'College of Life Science, Chinese PLA General Hospital, Beijing, 'The First Clinical Medical College, Nanchang University, Nanchang, China

\section{Key Words}

Ovarian germline stem cells $•$ Notch signaling $•$ DAPT $•$ Mice

\begin{abstract}
Background/Aims: Ovarian germline stem cells (OGSCs) have been shown to mainly exist in the ovarian surface epithelium (OSE), but the activity changes of germline stem cells during different reproductive stages and the potential regulatory signaling pathway are still unknown. The Notch signaling pathway plays a key role in cell development, primordial follicles and stem cell proliferation. However, whether it plays a role in the proliferation of OGSCs is unknown. Here, we analyzed the activity changes of germline stem cells and the correlation between germline stem cells and the Notch signaling pathway. Methods: The expression of germline stem cell markers Mvh, Ooc4 and the Notch molecules Notch1, Hes1, and Hes5 were detected during 3 days (3d), and 2, 12, 20 months $(2 \mathrm{~m}, 12 \mathrm{~m}, 20 \mathrm{~m})$ mouse ovarian surface epithelium samples. DAPT, a specific inhibitor of the Notch pathway, was used to observe the influence of Notch signaling in the germline stem cells. Results: The results showed that the levels of MVH and OCT4 decreased substantially with reproductive age in ovarian surface epithelium, and the same tendency was detected in the Notch signaling molecules Notch1, Hes1 and Hes5. Dual-IF results showed that the germline stem cell markers were co-expressed with Notch molecules in the ovarian surface epithelium. While, the expression of MVH and OCT4 were reduced when the ovaries were treated with DAPT and the levels were attenuated with increasing dose of DAPT. Conclusion: Taken together, our results indicate that the viability of OGSCs decreased with the age of the mouse ovaries, and the activity of OGSCs in the ovarian surface epithelium may be related to the Notch signaling pathway.
\end{abstract}




\section{Cellular Physiology Cell Physiol Biochem 2015;37:2311-2322 and Biochemistry Published online: December 04, 2015 le $\begin{aligned} & \text { DOI: } 2015 \text { The Author(s). Published by S. Karger AG, Basel } \\ & \text { www.karger.com/cpb }\end{aligned}$ \\ Pan et al.: The Expression of OGSCs and the Correlation with Notch Pathway}

\section{Introduction}

As a highly conserved cell signaling pathway, the Notch signaling pathway plays a crucial role in cell fate determination, cell proliferation and differentiation $[1,2]$. The Notch receptor is a single pass transmembrane protein, ligand proteins binding to the extracellular domain induce proteolytic cleavage and release of the Notch intracellular domain (NICD). Finally, the NICD moves into the nucleus to regulate the expression of Notch target genes [3]. Notch signaling pathway is necessary for cell-cell communication, which involves gene regulation mechanisms that control multiple cell proliferation and differentiation processes during embryonic and adult life. Previously, Notch signaling pathway is accepted as one of key pathway in the formation and development of primordial follicles $[4,5]$. Recent studies have confirmed that the Notch signaling is involved in the proliferation and differentiation of various stem cells [6-8]. Especially, these researches have shown that the Notch signaling pathway is also involved in the regulation of germline stem cells in invertebrates $[9,10]$. However, it is still unknown that the role of Notch pathway in germline stems cells of mammalians ovary.

Compared with males, there is a limited reproductive cycle for female mammals during the whole life. In mouse ovaries, due to a large number of reproductive follicles that rupture at birth, the limited remaining germ cells are eventually wrapped in primitive granulosa cells and to form the primordial follicle pool $[11,12]$. As we known, the traditional view may suggest that the ovarian function gradually decrease with the female ages. One of the major reasons is that the consumption of the primordial follicle pool is greater than its replenishment [13]. The balance between consumption and replenishment determines ovarian function and reproductive span, so the continuous replenishment to primordial follicle pool can maintain the ovarian function, delay premature ovarian aging and restore ovarian function.

The OSE has been confirmed to be a source of oocytes during the embryonic or fetal period, therefore, it is also commonly taken as the germinal epithelium. OGSCs or female germline stem cells (FGSCs) are a type of germ cell that possesses the abilities of proliferation and differentiation. In recent years, these cells have been proven to mainly exist in the OSE, which can generate oocytes to replenish the primordial follicle pool [14-16]. At present, OGSCs have been successfully isolated and cultured in vitro via the primary culture method from neonatal and adult mouse ovaries [16-18]. In addition, the OGSCs have also been successfully isolated from other postnatal mammalian ovaries [15, 19, 20]. Especially, the OGSCs from human ovaries were primary cultured and developed to a follicle-like cells in vitro $[21,22]$, which may provide a new therapeutic approach for ovary remodeling, infertility treatment and delaying female aging in future. As a tool, OGSCs had also been successfully used to construct transgenic animals $[15,23]$. The discovery of OGSCs provides enormous clinical application prospect, however, there are still some problems that need to be solved before the potential application of OGSCs can be realized. As a source of oocytes, the OSE layer may play a considerable role in OGSCs propagation and development. And the number or growth of OGSCs in OSE layer will benefit to replenish germ cell and save the ovarian function. However, the number or proliferation of OGSCs changes throughout the reproductive life cycle. Consequently, it is very meaningful that OGSCs can maintain stability for ovary function. Previous studies have indicated that the Notch pathway involves in the formation and development of primordial follicles, the regulation of OGSCs in invertebrates, as well as tumor stem cell proliferation. Hence, considering Notch signaling pathway plays a key role in stem cell proliferation and follicle development, we leaded Notch signaling pathway into the research of OGSCs in mouse. Here, the aim of this study is to reflect the changes in the number or growth of OGSCs in mouse OSE and detect the expression variation of the core components of the Notch pathway during different stages of the reproductive cycle. Further, we try to explore whether or not the number or proliferation of OGSCs in the OSE is related to the Notch signaling pathway. 


\section{Cellular Physiology Cell Physiol Biochem 2015;37:2311-2322 \begin{tabular}{l|l|l} 
and Biochemistry $10.1159 / 000438586$ & (c) 2015 The Author(s). Published by S. Karger AG, Basel \\
Published online: December 04, 2015 & www.karger.com/cpb
\end{tabular} Pan et al.: The Expression of OGSCs and the Correlation with Notch Pathway}

\section{Materials and Methods}

Animals

Kunming (KM) female mice were obtained from the Center of Experimental Animals, NanChang University, and they were used for all experiments; the mice had free access to food and water. All procedures involving mice were approved by the animal and ethical committee of NanChang University.

OSE collection and ovary culture

The intact ovaries of mice in different phases of the reproductive cycle were isolated and cleared from the ovarian appendage as much as possible. Then, the surface epithelium of whole ovary was collected, the whole protocol was performed according to previously described methods [24]. Briefly, the surface epithelial tissue of ovaries were collected by softly brushing the OSE with a small cytology brush under stereoscopic microscope, the fragment of epithelial tissues were washed with physiological solution and collected by centrifuge. In the end, the pellet was utilized to extract total mRNA and protein.

For ovary culture in vitro, the intact ovaries of postnatal 5- to 7-d-old mice were cultured using the Waymouth system (Sigma, USA) and supplemented with 10\% (v/v) FBS (Gibco, USA), 0.23 mM sodium pyruvate and 1\% penicillin and streptomycin (P/S) (Solarbio, China) [25]. In brief, the ovaries were removed as quickly as possible under sterile conditions, washed with pre-cooled D-Hanks solution and cleaned to remove the ovarian accessory and adipose tissue as much as possible. Then, the ovaries were allocated randomly into four groups and cultured on a gelatin sponge surface for $48 \mathrm{~h}$ with $600 \mu \mathrm{l}$ of Waymouth medium supplemented with different concentrations of DAPT in a $\Delta 4$ hole plate (Nunc, Denmark). The medium was changed every $24 \mathrm{~h}$ with the replacement of half fresh medium. The culture experiment was repeated at least in triplicate.

\section{Quantitative real-time PCR}

Total RNA was extracted with Tri-reagent (Life Technology, USA) from the OSE of mice of different reproductive stages. The whole protocol was performed according to previously described methods [24]. For 3-d-old or 5- to 7-d-old ovaries, more than 10 ovaries were necessary to extract enough total RNA, and for 2-, 12- and 20-m-old ovaries, two ovaries were needed to extract sufficient total RNA. The cDNA was synthesized using a PrimeScript RT reagent Kit with a gDNA Eraser (TaKaRa, Japan). Amplification was performed on an ABI7000 PCR instrument (Applied Biosystems, Foster City, CA, USA) using three-stage program parameters according to the manufacturer's instructions: $2 \mathrm{~min}$ at $50^{\circ} \mathrm{C}, 2 \mathrm{~min}$ at $95^{\circ} \mathrm{C}$, and then 40 cycles of $15 \mathrm{~s}$ at $95^{\circ} \mathrm{C}$ and $60 \mathrm{~s}$ at $60^{\circ} \mathrm{C}$, followed by a final cooling step at $4^{\circ} \mathrm{C}$. The primers designed for PCR are shown in Table 1 . The reaction was carried out in a 20- $\mu$ l volume containing $10 \mu \mathrm{l}$ of SYBR green Master Mix (Life Technology, USA), $0.5 \mu \mathrm{l}$ of cDNA, $0.6 \mu \mathrm{l}$ of $50 \mathrm{mM} \mathrm{MgCl} 2,1.6 \mu \mathrm{l}$ of $10 \mu \mathrm{M}$ primers, and sterilized

Table 1. Primer sequences used for quantitative real time PCR

\begin{tabular}{|c|c|c|}
\hline Gene & Primer Sequence( $\left.5^{\prime}-3^{\prime}\right)$ & Gene Number \\
\hline \multirow{2}{*}{ Notch1 } & Forward: CAACCAGACAGACCGCACCG & \multirow{2}{*}{ NM_008714.3 } \\
\hline & Reverse: CAGCAGCATCCACATTGTTCACC & \\
\hline \multirow{2}{*}{ Hes1 } & Forward: CCAGCCAGTGTCAACACGA & \multirow{2}{*}{ NM_008235.2 } \\
\hline & Reverse: AATGCCGGGAGCTATCTTTCT & \\
\hline \multirow{2}{*}{ Hes 5} & Forward: AGTCCCAAGGAGAAAAACCGA & \multirow{2}{*}{ NM_010419.4 } \\
\hline & Reverse: GCTGTGTTTCAGGTAGCTGAC & \\
\hline \multirow{2}{*}{$M v h$} & Forward: GTGTATTATTGTAGCACCAACTCG & \multirow{2}{*}{ NM_001145885.1 } \\
\hline & Reverse: CACCCTTGTACTATCTGTCGAACT & \\
\hline \multirow{2}{*}{ Oct-4 } & Forward: AGCTGCTGAAGCAGAAGAGG & \multirow{2}{*}{ NM_013633.3 } \\
\hline & Reverse: GGTTCTCATTGTTGTCGGCT & \\
\hline \multirow{2}{*}{ Gapdh } & Forward: ACGTGCCGCCTGGAGAAAC & \multirow{2}{*}{ NM_001289726.1 } \\
\hline & Reverse: GTCCTCAGTGTAGCCCAAGATGC & \\
\hline
\end{tabular}




\section{Cellular Physiology Cell Physiol Biochem 2015;37:2311-2322

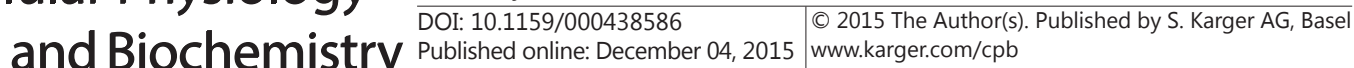 \\ Pan et al.: The Expression of OGSCs and the Correlation with Notch Pathway}

distilled water up to $20 \mu \mathrm{l}$. All assays were independently repeated at least in triplicate, and GAPDH was used as the reference gene.

Immunohistochemistry (IHC) and immunofluorescence

Ovaries ( $n=5)$ were individually fixed with $4 \%$ paraformaldehyde overnight. The total immunostaining protocol was performed according to previously described methods [26]. The primary antibodies used in this study are as follows: MVH (Abcam, ab27591), OCT4 (Proteintech, 11263-1-AP), NOTCH1 (Abcam, ab52627), HES1 (Abcam, ab108937), HES5 (Abcam, ab25374), and BrdU (Abcam, ab8152). All antibodies were diluted at 1:100 except Oct4, which was diluted at 1:200. All of the images were examined under a NIKON Eclipse 80i microscope.

\section{Western blot analysis}

Total protein was extracted from mouse ovaries using RIPA lysis solution (Beyotime, P0013C) according to the previous literature [27]. For 3-d-old or 5- to 7-d-old ovaries, owing to their small size, more than 100 ovaries were needed to extract sufficient total protein. For 2-, 12- and 20-m-old ovaries, more than 10 ovaries were needed to extract enough total protein. Briefly, the OSE was adequately ground using a PowerMasher (Optima INC), and the whole lysates were collected by centrifugation at 12,000 rpm for 15 $\mathrm{m}$ at $4^{\circ} \mathrm{C}$. Then, the supernatants were mixed with the corresponding volume of $5 \times$ loading buffer (Solarbio, China) and boiled for $5 \mathrm{~min}$. The total proteins were then subjected to SDS-PAGE. After electrophoresis, the proteins were transferred onto a PVDF membrane (Millipore, USA). The membrane was blocked with 5\% skim milk in TBST buffer for $20 \mathrm{~m}$ at room temperature and then immunoblotted overnight at $4{ }^{\circ} \mathrm{C}$ with the following primary antibodies: MVH (Abcam, ab13840, 1:500), OCT4 (Proteintech, 11263-1-AP, 1:500), NOTCH1 (Abcam, ab52627, 1:1000), HES1 (Abcam, ab108937, 1:1000), HES5 (Abcam, ab25374, 1:1000), and GAPDH (Abcam, ab37168, 1:2500). All experiments were repeated at least three times.

\section{Statistical analysis}

The quantitative data are shown as the mean \pm SD. The statistical comparisons among the different age groups or DAPT groups were analyzed using either Student's t test to compare two conditions or ANOVA followed by planned comparisons of multiple conditions; $\mathrm{p}<0.05$ was considered to be significant, and $\mathrm{p}<0.01$ and $\mathrm{p}<0.001$ were considered extremely significant.

\section{Results}

The expression tendency of germline stem cell markers and key Notch pathway molecules in the mouse OSE

It has been previously confirmed by other studies that OGSCs are mainly located in the OSE $[14,16]$. To detect the viability of germline stem cells and the activity of the Notch signaling pathway in mouse OSE at different stages, we selected five candidate genes, including Mvh, Oct4, Notch1, Hes1 and Hes5. We chose 3-d-, 2-m-, 12-m- and 20-m-old mice to analyze the mRNA and protein expression levels of these genes in the OSE. The real-time PCR results showed that the mRNA level of Mvh and Oct4 were the highest in 3-d-old mice and were extremely down-regulated in 2-m-old mice. There was little Mvh and Oct4 expression in 12- and 20-m-old mice ( $<0.05$ ) (Fig. 1A). The key components of the Notch pathway (Notch1, Hes1 and Hes5) were significantly reduced along with the increasing reproductive age. However, compared with Mvh and Oct4, expression of these Notch pathway molecules was still observed at $12-\mathrm{m}$ and $20-\mathrm{m}(\mathrm{p}<0.05)$ (Fig. 1B). Next, we detected the protein level of the above candidate genes. The western blotting results showed similar trends in protein expression that correspond with the mRNA expression results $(\mathrm{p}<0.05)$ (Fig. 1C, D).

Meanwhile, we gathered 3-d-, 2-m- and 20-m postnatal mouse ovaries. The Hematoxylinsosin (H\&E) staining indicated that there are some of very small epiblast-like stem cells (VSELs) in the OSE at 3-d and 2-m OSE, a few level at 20-m, and the results of a smear of OSE cells showed the same phenomena (Fig. 2A). The IHC results showed that MVH and OCT4 expression was highest in the OSE at 3-d, a higher level was observed at 2-m, and there was less or no staining at 20-m (Fig. 2B). In addition, we detected the expression of 
A
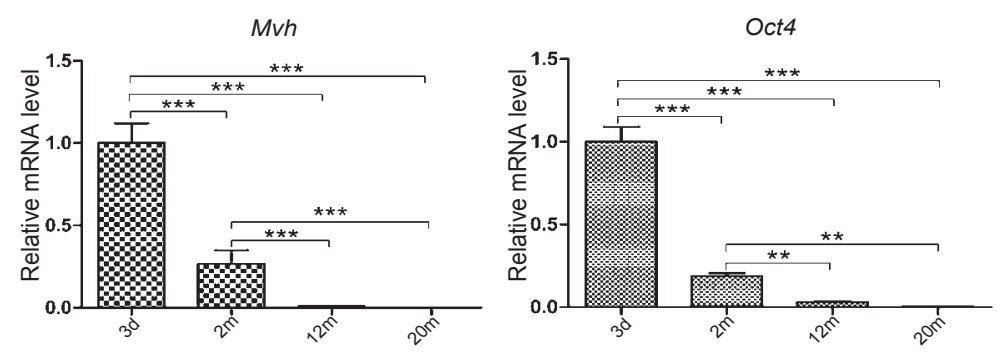

B
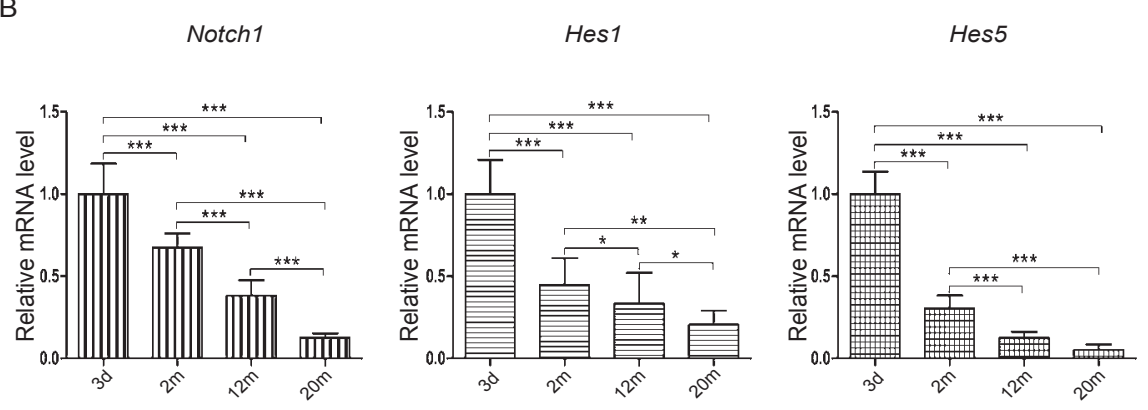

C
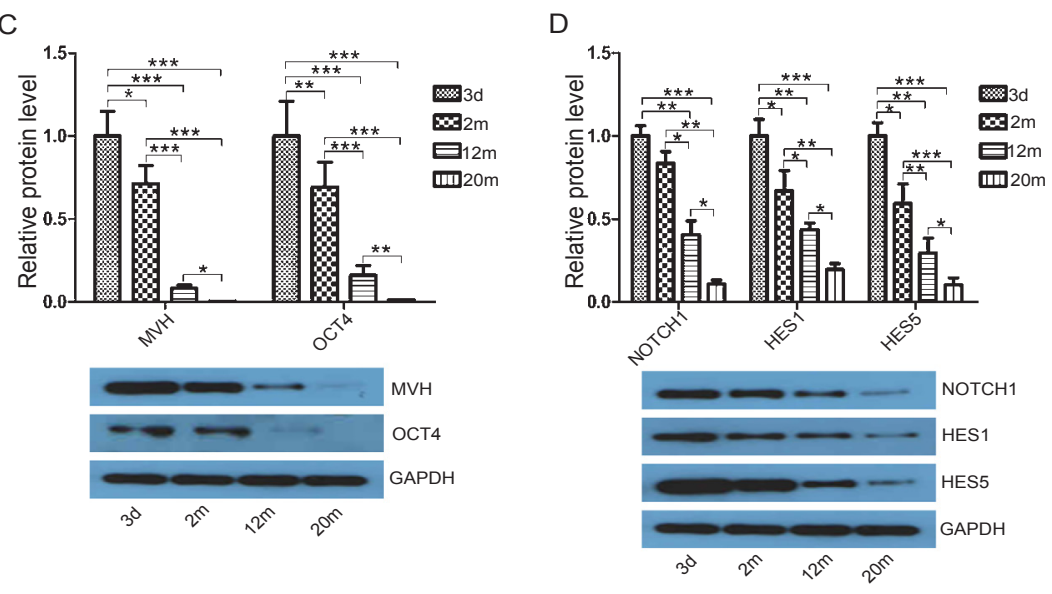

Fig. 1. Expression of germline stem cell markers and notch pathway components in different stage of mice OSE. (A) Quantitative real-time PCR analysis for germline stem cell markers in 3-d-, 2-m-, 12-m and 20-m mice OSE. The expression of Mvh and Oct4 were relatively highest level at 3-d, and displayed at least $60 \%$ decrease at 2-m, extremely decreased at 12-m and almost cannot detected at 20-m. (B) compared with 3-d, Notch1 mRNA level in 20-m displayed an 80\% decrease, a 70\% decrease in Hes1 and a 90\% decrease in Hes5. (C) Western bolt analysis for the protein level of MVH and OCT4 in 3-d-, 2-m-, 12-m and 20-m mice OSE. D: The protein expression of notch pathway components NOTCH1, HES1 and HES5 in 3-d-, 2-m-, 12-m and 20 -m mice OSE. The results present as the mean \pm SD. ${ }^{*} \mathrm{p}<0.05$, ${ }^{* *} \mathrm{p}<0.01$.

Notch signaling components, the results showed that the expression levels of NOTCH1, HES1 and HES5 were localized in the OSE in all three age stages, but compared to the results at 3-d, there was an obvious decrease in expression at 2-m (Fig. 2C). Together, in this study it has been evidenced that the germinal marker Mvh (expressed also in OGSCs) along with Oct4 was indeed expressed in the OSE, and these results indicate that the expression level of germline stem cell markers and key Notch pathway molecules in the OSE of mouse decreased with ovary age. 


\section{Cellular Physiology and Biochemistry Published online: December 04,2015 $\begin{aligned} & \text { (c) 2015 The Author(s). Published by S. Karger AG, Basel } \\ & \text { www.karger.com/cpb }\end{aligned}$

Fig. 2. The protein expression and dynamic changes of germline stem cell markers and Notch pathway components in OSE. The scale bars $20 \mu \mathrm{m}$. (A) Hematoxylin-sosin staining the OSE and a smear of OSE cells in 3-d, 2-m and 20-m mice. Some VSELs present in OSE, but there are a decrease trend along with aging. (B) Immunohistochemistry analysis the expression of MVH and OCT4 in 3-d, 2-m and 20-m OSE. The arrow represents a positive cell. MVH and OCT4 were highest level in 3-d OSE, and a higher level was observed in 2-m, there was less or no staining in 20-m. (C) Notch pathway components expression in all three age stages OSE, but there were a decrease trend along with reproductive aging.

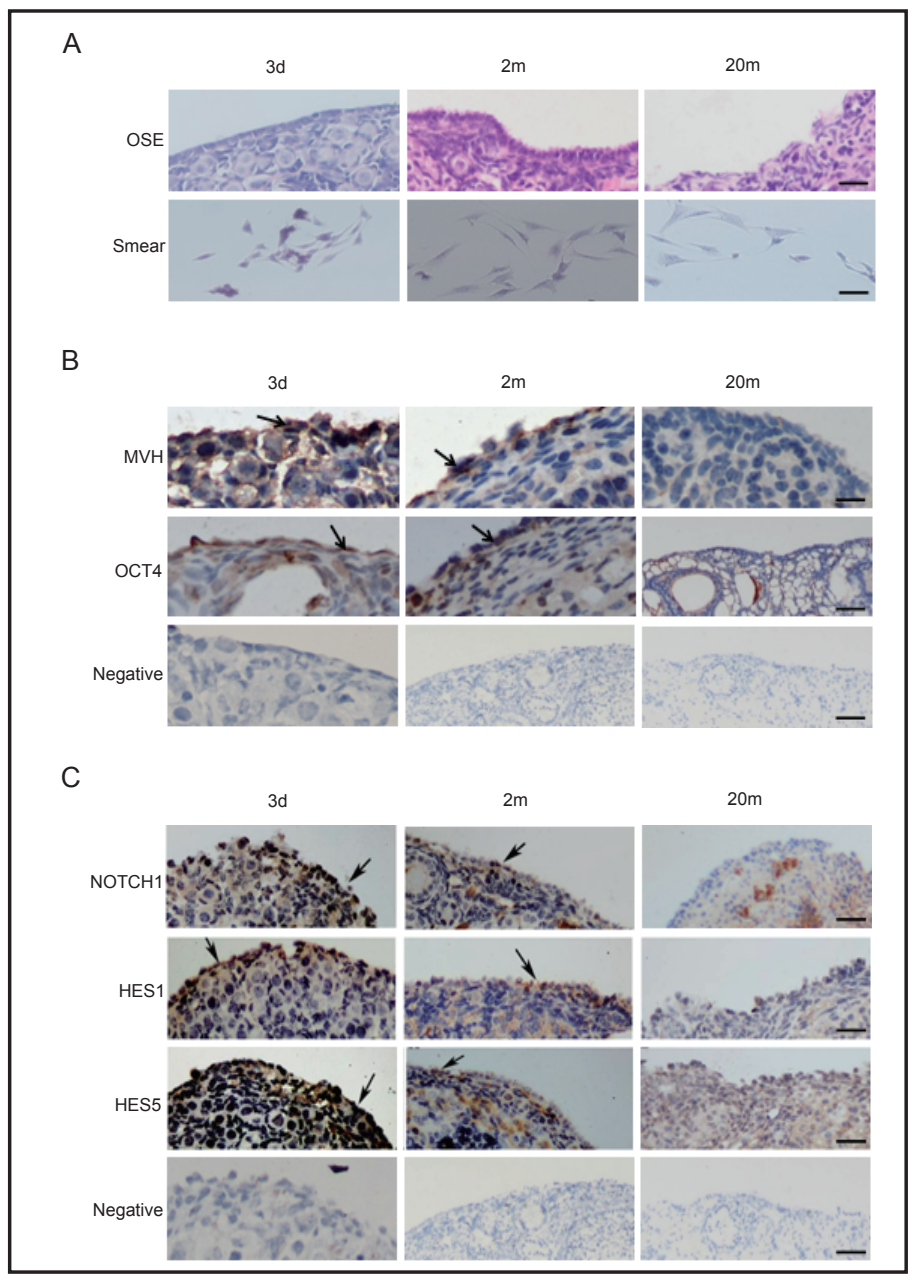

Germline stem cell markers and Notch components are co-expressed in the ovary cortical layer

We adopted dual-immunofluorescence histochemistry (Dual-IF) to detect the coexpression between germline stem cell markers and Notch molecules in the OSE. The Dual-IF results showed that MVH (green) and NOTCH1 (red) are co-expressed in the cortical layer of ovaries in a pattern that showed the strongest expression at 3-d, clearly decreased expression at 2-m and almost undetectable expression at 20-m (Fig. 3A). Similar co-expression patterns appeared for both MVH (green) and HES1, BrdU (red) (Fig. 3B, C). In addition, in cell level, we isolated OGSCs which showed less $20 \mu \mathrm{m}$ diameter and oval shape by primary culture using mice ovaries, and Dual-IF results showed that MVH and OCT4 are co-expressed in the OGSCs in vitro culture (Fig. 3D).

Inhibition of Notch signaling decreased the expression of germline stem cell markers

To further examine the correlations between OGSCs and the Notch pathway, 5- to -7-d-old mouse ovaries were treated with the specific inhibitor DAPT to block the Notch pathway. Mouse ovaries were divided into four groups: the DMSO group, the $10 \mu \mathrm{M}$ DAPT group, the $20 \mu \mathrm{M}$ DAPT group and the $40 \mu \mathrm{M}$ DAPT group. All groups except the DMSO group were treated with DAPT for $48 \mathrm{~h}$. The real-time PCR results showed that compared with the DMSO group, the mRNA level of Mvh was slightly decreased in the $10 \mu \mathrm{M}$ DAPT group and decreased by nearly $50 \%$ in the $20 \mu \mathrm{M}$ group $(\mathrm{p}<0.05)$. However, there was no further decrease in the $40 \mu \mathrm{M}$ group compared to the $20 \mu \mathrm{M}$ group. Meanwhile, the mRNA level of Oct4 did not demonstrate a clear reduction in the $10 \mu \mathrm{M}$ group, but there was an evident decrease in the $20 \mu \mathrm{M}$ group $(\mathrm{p}<0.05)$ and a much greater decrease in the $40 \mu \mathrm{M}$ group $(\mathrm{p}<$ KARGER 


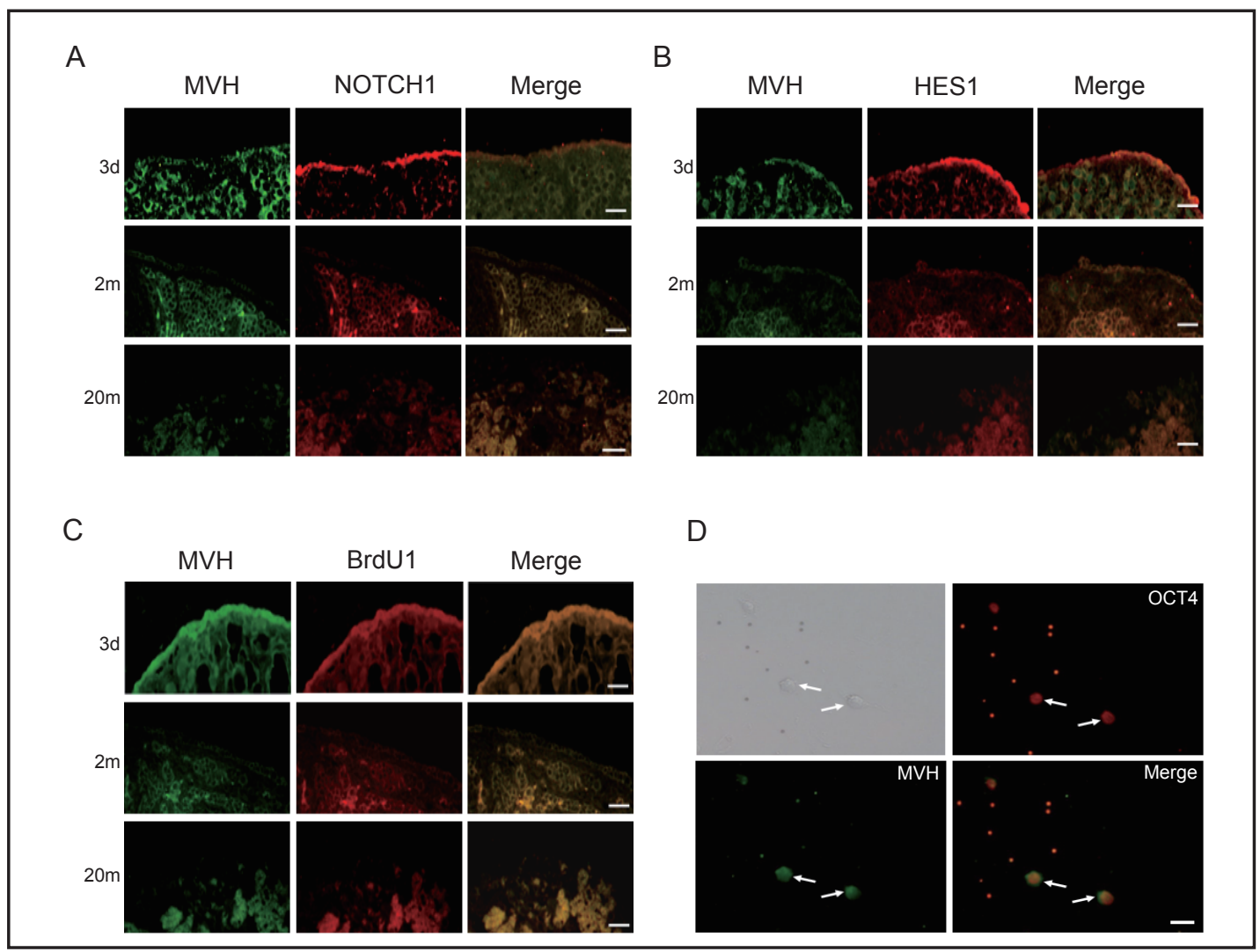

Fig. 3. The co-expressoin of germline stem cells marker and Notch components in ovary cortical layer. Dual-IF was performed to co-locate the MVH and Notch components in different reproductive stages OSE. The scale bars $20 \mu \mathrm{m}$. (A) There was a strongest expression for MVH (green) and NOTCH1 (red) in 3-d OSE, a evidently decreased in 2-m and almost a undetectable expression in 20-m. (B and C) The similar co-expression patterns appeared both MVH, (green) and HES1, BrdU (red) in different reproductive stages. (D) Dual-immunocytochemistry results showed that MVH (green) and OCT4 (red) co-expressed in the OGSCs in vitro culture.

0.05) (Fig. 4A). In addition, western blot results showed that MVH protein expression was slightly decreased in the $10 \mu \mathrm{M}$ and $20 \mu \mathrm{M}$ groups, and there was an almost $50 \%$ decrease in the $40 \mu \mathrm{M}$ group ( $\mathrm{p}<0.05$ ) (Fig. 4C). OCT4 protein levels demonstrated a successive downregulation along with the increasing DAPT concentration (Fig. 4C). And we also measured the downergulation of Notch signaling following DAPT treatment, the results showed that the mRNA level of two key target genes Hes1 and Hes5 were a successive decrease with increasing dose of DAPT ( $<<0.05$ ) (Fig 4B). In general, target protein HES1 and HES5 also showed a downward trend $(\mathrm{p}<0.05)$ (Fig 4D).

Attenuating Notch signaling decreased the activity of germline stem cells in the ovary cortical layer

Mouse ovaries were collected 5- to -7-d postnatal and treated with $20 \mu \mathrm{M}$ and $40 \mu \mathrm{M}$ DAPT for $48 \mathrm{~h}$. Dual-IF was performed to detect the expression changes of MVH and OCT4 in the OSE. The results showed that compared with the DMSO group, the $20 \mu \mathrm{M}$ DAPT group showed a significant decrease, and a much greater decrease was observed in the $40 \mu \mathrm{M}$ group. The above results suggest that Notch signaling contributes to the viability of germline stem cells (Fig. 4E). Taken together, these findings suggest that the Notch pathway may relate to the viability or proliferation of germline stem cells in the OSE of mouse. 
Fig. 4. Expression changes of Mvh and Oct4 in OSE after treated with inhibitor DAPT. (A) Quantification real-time PCR analysis for the relative mRNA expression of Mvh and Oct4 after treated ovaries with increasing dose of DAPT. Compared with DMSO group, the mRNA level of Mvh was decreased in $20 \mu \mathrm{M}$ group and $40 \mu \mathrm{M}$ group, and Oct4 was an evident decrease in $20 \mu \mathrm{M}$ group and more decrease in $40 \mu \mathrm{M}$. (B) The similar results were detected in Notch signaling pathway target gene Hes1 and Hes5. (C) Western blot analysis results showed MVH protein displayed a little decrease in $10 \mu \mathrm{M}$, $20 \mu \mathrm{M}$ groups, and an almost $50 \%$ decrease in 40 $\mu \mathrm{M}$ group, OCT4 protein level displayed a successive down-regulation. (D) Target protein HES1 and HES5 also showed a downward trend. (E) Dual-IF results showed that there was a well change in OSE after inhibited Notch pathway activity. The results present as the mean \pm SD. ${ }^{*} \mathrm{p}<0.05$, ${ }^{* *} \mathrm{p}<0.01$.
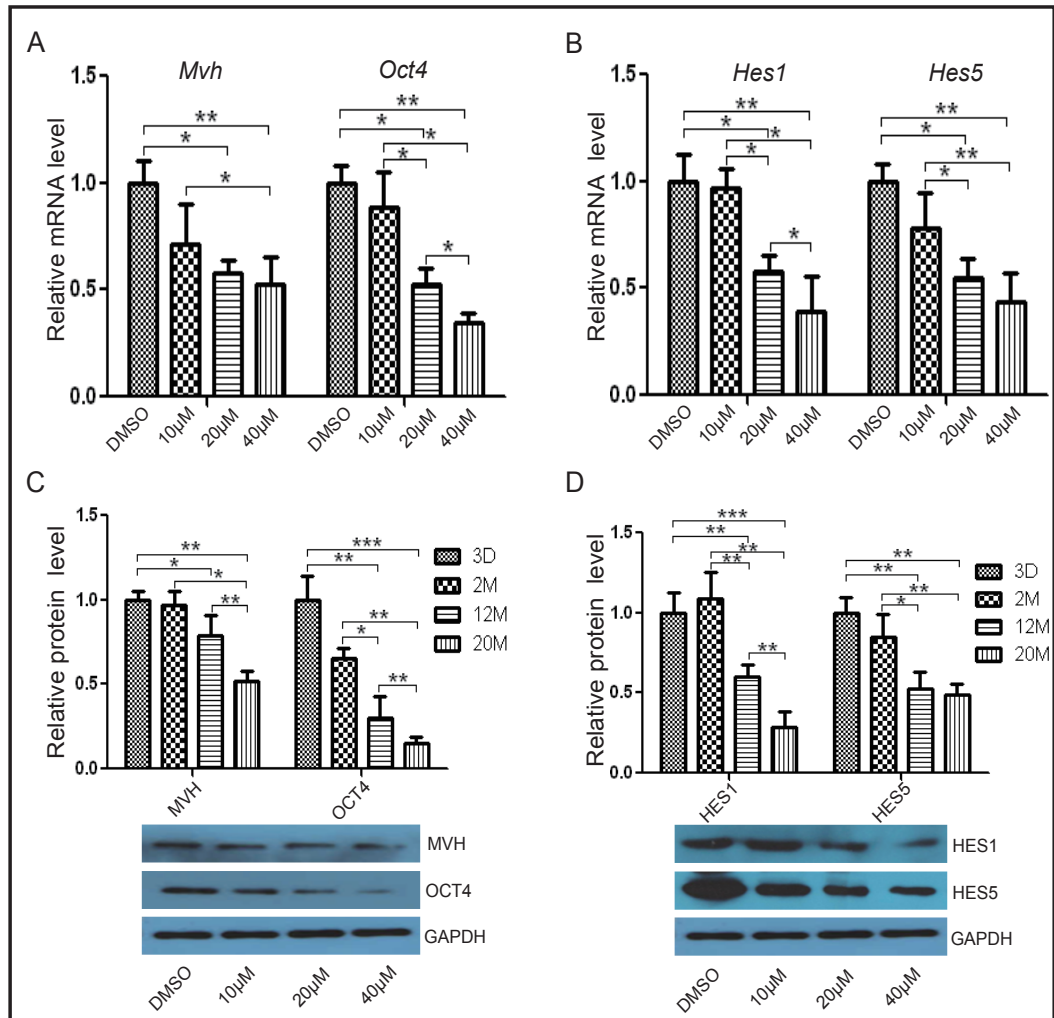

D

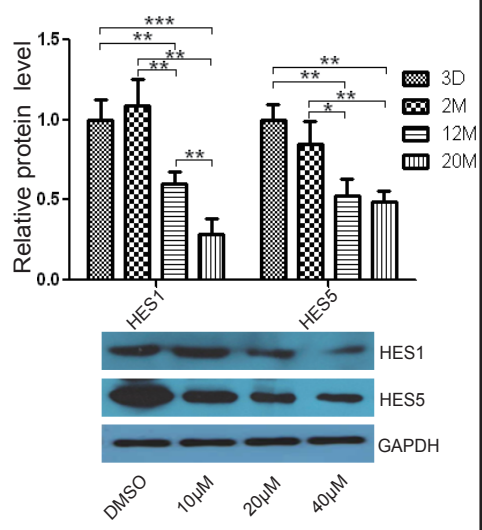

E
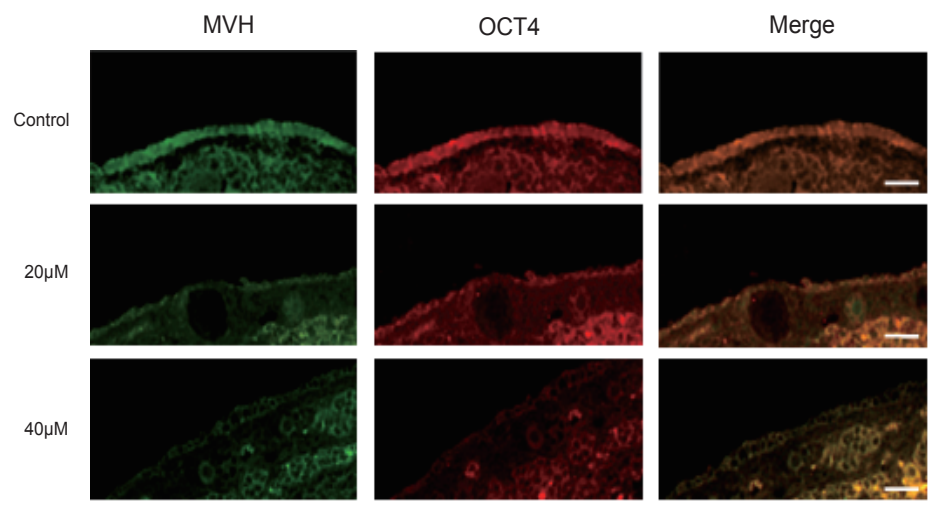

\section{Discussion}

Mvh is the homolog of the Drosophila vasa gene, which is specifically expressed in all germ cell lineages and is known as a specific marker of reproductive cells [28, 29]. Oct4 belongs to the POU family that plays a key role in embryonic development and stem cell pluripotency, it is specifically expressed in pluripotent stem cells [30-33]. Therefore, in general, Mvh and Oct4 are taken as the markers of germ stem cells. The NOTCH1 surface receptor is a key molecule in the Notch pathway; their expression can prompt the activity of the Notch pathway [34, 35]. Hairy and enhancer of split 1 (Hes1) and hairy and enhancer of split 5 (Hes5) are the principal target genes of the Notch pathway, which regulate the proliferation and differentiation of cells [36, 37]. Hence, the expression levels of Notch1, Hes1 and Hes5 represent the activity of the Notch signaling pathway. Here, we selected Mvh and Oct4 to represent the activity or proliferation of germline stem cells, and selected Notch1, Hes1 and Hes5 to represent the activity of Notch signaling pathway. 


\section{Cellular Physiology Cell Physiol Biochem 2015;37:2311-2322 \\ \begin{tabular}{l|l|l} 
and Biochemistry $\begin{array}{l}\text { DOI: 10.1159/000438586 } \\
\text { Published online: December 04, } 2015\end{array}$ & $\begin{array}{l}\text { (c) } 2015 \text { The Author(s). Published by S. Karger AG, Basel } \\
\text { www.karger.com/cpb }\end{array}$
\end{tabular} \\ Pan et al.: The Expression of OGSCs and the Correlation with Notch Pathway}

The replenishment of OGSCs and their consumption maintains the balance of the follicle pool [13]. Female mammals gradually lose reproductive ability and become infertility with ovary aging. One of the reasons for these changes in fertility is a decline of the ovarian somatic niche function. Besides, the consumption of the follicle pool is faster than the replenishment of the OGSCs, especially, a decrease in the number and proliferation ability of OGSCs in the OSE maybe accelerates the coming of menopause. Our results also show that the mRNA and protein levels of both Mvh and Oct4 decreased with ovary age. As shown in Fig. 1A, compared with the 3-d group, Mvh and Oct4 displayed decreased expression by more than half in the 2 -m group, and there was very little expression in 12-m-old mice or, more dramatically, in the $20-\mathrm{m}$ group. We demonstrated that the activity or proliferation of germline stem cells in the OSE will decrease as the age goes on, and our results explain one of the possible causes of infertility in old mice.

The OGSCs are mainly present in the surface epithelium, and they are characterized by their small number and low proliferation ability [21, 24]. According to ovary morphometric analysis results [13], we chose 3-d-, 2-m- and 20-m-old mouse ovaries as our experimental groups for the IHC study to represent the reproductive cycle of neonatal, adolescent and gerontal mice, respectively. The IHC results showed that both MVH and OCT4 were expressed at the highest levels in the OSE of 3-d-old mice. There was an evident decrease in 2-m-old mice, and expression was almost undetectable in $20 \mathrm{~m}$ old mice. The results suggested that the highest numbers and activities of OGSCs occur during the neonatal period, and these values decrease with increasing reproductive age (Fig. 2B).

The proliferation capacity of OGSCs has a direct impact on the maintenance and remodeling of ovarian function. However, at present, the proliferative mechanism of OGSCs is still unknown. Therefore, exploring the regulatory mechanism of OGSCs may help us develop methods to maintain the balance of the follicle pool and delay ovarian aging. As one of the most important cell signaling pathways, the Notch signaling pathway was detected to exist in both vertebrate and invertebrate ovaries. As a classical Notch signaling pathway, the CBF$1 /$ RBP-Jk pathway plays a pivotal role in mammals [38]. Studies have shown that adjacent cells transfer Notch signals to each other via the binding of receptors and ligands through a signaling cascade to regulate cellular behavior, including, proliferation, development, organ formation and morphogenesis [38, 39]. In general, the ligand such as JAGGED, which can be combined with membrane receptor NOTCH1 to conduct signals, eventually activates the expression of the primary target genes Hes1 and Hes5; the latter was shown to regulate cell proliferation and differentiation $[40,41]$. In fact, study indicated that Notch signaling is active in mouse ovary, the Notch components (Notch1,2 and 3) and effectors (Hes1 and Hes5) are differentially expressed during follicles and corpora lutea development throughout the oestrous cycle [42]. And some studies have also shown that Notch pathway is involved in the formation of primordial follicles and that there is an intimate connection between this pathway and mammalian ovarian function $[4,43]$. As important components of notch pathway, the mRNA or protein expression levels of Notch1, Hes1 and Hes5 represent the Notch pathway activities. The real-time PCR results showed that Notch1, Hes1 and Hes5 are expressed in mouse ovaries of different phases, but they had their highest expression levels in 3-d-old ovaries and their weakest expression at $20-\mathrm{m}$, which confirmed that Notch pathway activity decreased with reproductive age. However, there is still detectable expression of Mvh or Oct4 in 12-m and 20-m-old mouse ovaries (Fig. 1B). At the protein expression level, the western blot results showed the corresponding decrease in expression with reproductive age (Fig. 1C, D). Moreover, the Notch signaling components displayed a similar trend compared with germline stem cell markers.

Is there a correlation between germline stem cells activity and the Notch signaling pathway? To address this question, we used 3-d-, 2-m- and 20-m-old mouse ovaries. The dual-IF results showed that MVH is co-expressed with NOTCH1 in the OSE, and both of them are expressed at their highest level in 3-d-old mice, followed by 2-m-old mice, and very little expression was observed in 20-m-old mice (Fig. 3A). The same results were observed for MVH and HES1 (Fig. 3B). In addition, for observing the proliferative activity in OSE, we also 


\section{Cellular Physiology Cell Physiol Biochem 2015;37:2311-2322 \begin{tabular}{ll|l} 
DOI: 10.1159/000438586 & O 2015 The Author(s). Published by S. Karger AG, Basel \\
www.karger.com/cpb
\end{tabular} \\ Pan et al.: The Expression of OGSCs and the Correlation with Notch Pathway}

detected the co-expression between MVH and BrdU, the results showed the strongest BrdU expression at 3-d, clearly decreased expression at 2-m and almost undetectable expression at 20-m (Fig. 3C). In a previous study, it was confirmed that OGSCs are mainly located in the OSE, so our results indicated that the Notch pathway may be involved in the regulation of germline stem cell proliferation in the ovarian cortical layer. The Notch signaling pathway was shown to participate in the formation of OGSCs niche and play a critical role in germline stem cell self-renewal and differentiation $[10,44]$. To further confirm the link between germline stem cells and the Notch signaling pathway in mouse ovarian tissues, the 5- to 7-d-old mouse ovaries were isolated and treated with the inhibitor DAPT. As an inhibitor of $\gamma$-secretase, DAPT has been widely used to block the Notch signaling pathway $[45,46]$. In our study, the mouse ovaries were continuously exposed to DAPT for $48 \mathrm{~h}$. Compared with the control, all DAPT-treated groups demonstrated reduced mRNA and protein expression of Mvh and Oct4 (Fig. 4A,C). Our dual-IF results also showed that the DAPT-treated groups showed a slight attenuation of MVH and OCT4 expression in the OSE compared with the DMSO group (Fig. 4E). Therefore, our data suggested that the Notch signaling pathway may be a potential pathway involved in the regulation of germline stem cells.

In the present study, we mainly focused on OSE studies. As a next step, we will prepare to explore the correlation between the Notch pathway and OGSCs at the cell level, and cell experiments will further clarify the regulation mechanism of OGSCs. At present, we have isolated and cultured the OGSCs via the primary culture method in vitro, and dual-IF results showed that MVH and OCT4 are co-expressed in the OGSCs (Fig. 3D). Next, we will prepare to detect and explore the proliferation changes after activating or inhibiting the Notch signaling pathway at the cellular level.

In conclusion, our data showed that the numbers or activity of OGSCs in OSE will decrease along with the increased reproductive age. And the activity of germline stem cells in the mouse OSE is related to the Notch signaling pathway. We hope our study provides some novel evidence that the Notch signaling pathway may be a key pathway in regulating the proliferation of germline stem cells in mammals.

\section{Acknowledgments}

We thank all of the members of our lab. This work was supported by the National Natural Science Foundation of China (No. 81160081, No. 81360100, No. 81260098), the Excellence 555 Engineering of Jiangxi Province, the Natural Science Foundation of JiangXi Province (No. 20142BAB205069, No. 20142BAB205002) and the Department of Public Health of JiangXi Province (No.20121156).

\section{Disclosure Statement}

None.

\section{References}

1 Haider S, Meinhardt G, Velicky P, Otti GR, Whitley G, Fiala C, Pollheimer J, Knofler M: Notch signaling plays a critical role in motility and differentiation of human first-trimester cytotrophoblasts. Endocrinology 2014;155:263-274.

2 Iso T, Kedes L, Hamamori Y: HES and HERP families: multiple effectors of the Notch signaling pathway. J Cell Physiol 2003;194:237-255.

3 Gokulan R, Halagowder D: Expression pattern of Notch intracellular domain (NICD) and Hes-1 in preneoplastic and neoplastic human oral squamous epithelium: their correlation with c-Myc, clinicopathological factors and prognosis in Oral cancer. Med Oncol 2014;31:126. 


\section{Cellular Physiology Cell Physiol Biochem 2015;37:2311-2322 \begin{tabular}{l|l|l}
\hline DOI: 10.1159/000438586 & $\begin{array}{l}\text { C } 2015 \text { The Author(s). Published by S. Karger AG, Basel } \\
\text { www.karger.com/cpb }\end{array}$ \\
\hline
\end{tabular}

4 Vanorny DA, Prasasya RD, Chalpe AJ, Kilen SM, Mayo KE: Notch signaling regulates ovarian follicle formation and coordinates follicular growth. Mol Endocrinol 2014;28:499-511.

5 Wang LQ Liu JC, Chen CL, Cheng SF, Sun XF, Zhao Y, Yin S, Hou ZM, Pan B, Ding C, Shen W, Zhang XF: Regulation of primordial follicle recruitment by cross-talk between the Notch and phosphatase and tensin homologue (PTEN)/AKT pathways. Reprod Fertil Dev DOI:10.1071/RD14212.

6 Jung SR, Song NJ, Yang DK, Cho YJ, Kim BJ, Hong JW, Yun UJ, Jo DG, Lee YM, Choi SY, Park KW: Silk proteins stimulate osteoblast differentiation by suppressing the Notch signaling pathway in mesenchymal stem cells. Nutr Res 2013;33:162-170.

7 Piccin D, Yu F, Morshead CM: Notch signaling imparts and preserves neural stem characteristics in the adult brain. Stem Cells Dev 2013;22:1541-1550.

8 You N, Liu W, Zhong X, Dou K, Tao K: Possibility of the enhanced progression of fetal liver stem/progenitor cells therapy for treating end-stage liver diseases by regulating the notch signaling pathway. Arch Med Res 2012;43:585-587.

9 Kitadate Y, Kobayashi S: Notch and Egfr signaling act antagonistically to regulate germ-line stem cell niche formation in Drosophila male embryonic gonads. Proc Natl Acad Sci USA 2010;107:14241-14246.

10 Ward EJ, Shcherbata HR, Reynolds SH, Fischer KA, Hatfield SD, Ruohola-Baker H: Stem cells signal to the niche through the Notch pathway in the Drosophila ovary. Curr Biol 2006;16:2352-2358.

11 Pangas SA: Regulation of the ovarian reserve by members of the transforming growth factor beta family. Mol Reprod Dev 2012;79:666-679.

12 Stansfield FJ, Nothling JO, Allen WR: Growth and development of the ovary and small follicle pool from mid fetal life to pre-puberty in the African elephant (Loxodonta africana). BMC Vet Res 2012;8:119.

13 Johnson J, Canning J, Kaneko T, Pru JK, Tilly JL: Germline stem cells and follicular renewal in the postnatal mammalian ovary. Nature 2004;428:145-150.

14 Celik O, Celik E, Turkcuoglu I, Yilmaz E, Simsek Y, Tiras B: Germline cells in ovarian surface epithelium of mammalians: a promising notion. Reprod Biol Endocrinol 2012;10:112.

15 Zhou L, Wang L, Kang JX, Xie W, Li X, Wu C, Xu B, Wu J: Production of fat-1 transgenic rats using a post-natal female germline stem cell line. Mol Hum Reprod 2014;20:271-281.

16 Zou K, Yuan Z, Yang Z, Luo H, Sun K, Zhou L, Xiang J, Shi L, Yu Q, Zhang Y, Hou R, Wu J: Production of offspring from a germline stem cell line derived from neonatal ovaries. Nat Cell Biol 2009;11:631-636.

17 Hu Y, Bai Y, Chu Z, Wang J, Wang L, Yu M, Lian Z, Hua J: GSK3 inhibitor-BIO regulates proliferation of female germline stem cells from the postnatal mouse ovary. Cell Prolif 2012;45:287-298.

18 Pacchiarotti J, Maki C, Ramos T, Marh J, Howerton K, Wong J, Pham J, Anorve S, Chow YC, Izadyar F: Differentiation potential of germ line stem cells derived from the postnatal mouse ovary. Differentiation 2010;79:159-170.

19 Bai Y, Yu M, Hu Y, Qiu P, Liu W, Zheng W, Peng S, Hua J: Location and characterization of female germline stem cells (FGSCs) in juvenile porcine ovary. Cell Prolif 2013;46:516-528.

20 Parte S, Bhartiya D, Telang J, Daithankar V, Salvi V, Zaveri K, Hinduja I: Detection, characterization, and spontaneous differentiation in vitro of very small embryonic-like putative stem cells in adult mammalian ovary. Stem Cells Dev 2011;20:1451-1464.

21 Virant-Klun I, Skutella T, Stimpfel M, Sinkovec J: Ovarian surface epithelium in patients with severe ovarian infertility: a potential source of cells expressing markers of pluripotent/multipotent stem cells. J Biomed Biotechnol 2011;2011:381928.

22 Virant-Klun I, Zech N, Rozman P, Vogler A, Cvjeticanin B, Klemenc P, Malicev E, Meden-Vrtovec H: Putative stem cells with an embryonic character isolated from the ovarian surface epithelium of women with no naturally present follicles and oocytes. Differentiation 2008;76:843-856.

23 Zhang Y, Yang Z, Yang Y, Wang S, Shi L, Xie W, Sun K, Zou K, Wang L, Xiong J, Xiang J, Wu J: Production of transgenic mice by random recombination of targeted genes in female germline stem cells. J Mol Cell Biol 2011;3:132-141.

24 Virant-Klun I, Skutella T, Hren M, Gruden K, Cvjeticanin B, Vogler A, Sinkovec J: Isolation of small SSEA4-positive putative stem cells from the ovarian surface epithelium of adult human ovaries by two different methods. Biomed Res Int 2013;2013:690415.

25 Li-Ping Z, Da-Lei Z, Jian H, Liang-Quan X, Ai-Xia X, Xiao-Yu D, Dan-Feng T, Yue-Hui Z: Proto-oncogene c-erbB2 initiates rat primordial follicle growth via PKC and MAPK pathways. Reprod Biol Endocrinol 2010;8:66. 


\section{Cellular Physiology Cell Physiol Biochem 2015;37:2311-2322 \begin{tabular}{l|l|l|l|} 
DOI: 10.1159/000438586 & $\begin{array}{l}\text { C } 2015 \text { The Author(s). Published by S. Karger AG, Basel } \\
\text { www.karger.com/cpb }\end{array}$
\end{tabular} \\ Pan et al.: The Expression of OGSCs and the Correlation with Notch Pathway}

26 Roden AC, Maleszewski JJ, Yi ES, Jenkins SM, Gandhi MJ, Scott JP, Aubry MC: Reproducibility of Complement 4d deposition by immunofluorescence and immunohistochemistry in lung allograft biopsies. J Heart Lung Transplant 2014;33:1223-1232.

27 Zhang ZP, Liang GJ, Zhang XF, Zhang GL, Chao HH, Li L, Sun XF, Min LJ, Pan QJ, Shi QH, Sun QY, De Felici M, Shen W: Growth of mouse oocytes to maturity from premeiotic germ cells in vitro. PLoS One 2012;7:e41771.

28 Encinas G, Zogbi C, Stumpp T: Detection of four germ cell markers in rats during testis morphogenesis: differences and similarities with mice. Cells Tissues Organs 2012;195:443-455.

29 Li R, Thorup J, Sun C, Cortes D, Southwell B, Hutson J: Immunofluorescent analysis of testicular biopsies with germ cell and Sertoli cell markers shows significant MVH negative germ cell depletion with older age at orchiopexy. J Urol 2014;191:458-464.

30 Fan YX, Gu CH, Zhang YL, Zhong BS, Wang LZ, Zhou ZR, Wang ZY, Jia RX, Wang F: Oct4 and Sox2 overexpression improves the proliferation and differentiation of bone mesenchymal stem cells in Xiaomeishan porcine. Genet Mol Res 2013;12:6067-6079.

31 Lawrence PA, Casal J: The mechanisms of planar cell polarity, growth and the Hippo pathway: some known unknowns. Dev Biol 2013;377:1-8.

32 Rodriguez-Alvarez L, Manriquez J, Velasquez A, Castro FO: Constitutive expression of the embryonic stem cell marker OCT4 in bovine somatic donor cells influences blastocysts rate and quality after nucleus transfer. In Vitro Cell Dev Biol Anim 2013;49:657-667.

33 Zhou SY, Zhang C, Baradaran E, Chuck RS: Human corneal basal epithelial cells express an embryonic stem cell marker OCT4. Curr Eye Res 2010;35:978-985.

34 Munch J, Gonzalez-Rajal A, de la Pompa JL: Notch regulates blastema proliferation and prevents differentiation during adult zebrafish fin regeneration. Development 2013;140:1402-1411.

35 Murta D, Batista M, Silva E, Trindade A, Henrique D, Duarte A, Lopes-da-Costa L: Dynamics of Notch pathway expression during mouse testis post-natal development and along the spermatogenic cycle. PLoS One 2013;8:e72767.

36 Basak 0, Taylor V: Identification of self-replicating multipotent progenitors in the embryonic nervous system by high Notch activity and Hes5 expression. Eur J Neurosci 2007;25:1006-1022.

37 Kitagawa M, Hojo M, Imayoshi I, Goto M, Ando M, Ohtsuka T, Kageyama R, Miyamoto S: Hes1 and Hes5 regulate vascular remodeling and arterial specification of endothelial cells in brain vascular development. Mech Dev 2013;130:458-466.

38 Sweeney C, Morrow D, Birney YA, Coyle S, Hennessy C, Scheller A, Cummins PM, Walls D, Redmond EM, Cahill PA: Notch 1 and 3 receptor signaling modulates vascular smooth muscle cell growth, apoptosis, and migration via a CBF-1/RBP-Jk dependent pathway. FASEB J 2004;18:1421-1423.

39 Shi C, Qian J, Ma M, Zhang Y, Han B: Notch 3 protein, not its gene polymorphism, is associated with the chemotherapy response and prognosis of advanced NSCLC patients. Cell Physiol Biochem 2014;34:743-752.

40 Chen G, Sun L, Yu M, Meng D, Wang W, Yang Y, Yang H: The Jagged-1/Notch-1/Hes-1 pathway is involved in intestinal adaptation in a massive small bowel resection rat model. Dig Dis Sci 2013;58:2478-2486.

41 Liu J, Lu WG, Ye F, Cheng XD, Hong D, Hu Y, Chen HZ, Xie X: Hes1/Hes5 gene inhibits differentiation via down-regulating Hash1 and promotes proliferation in cervical carcinoma cells. Int J Gynecol Cancer 2010;20:1109-1116.

42 Murta D, Batista M, Silva E, Trindade A, Mateus L, Duarte A, Lopes-da-Costa L: Differential expression of Notch component and effector genes during ovarian follicle and corpus luteum development during the oestrous cycle. Reprod Fertil Dev DOI:10.1071/RD13399.

43 Manosalva I, Gonzalez A, Kageyama R: Hes1 in the somatic cells of the murine ovary is necessary for oocyte survival and maturation. Dev Biol 2013;375:140-151.

44 Song X, Call GB, Kirilly D, Xie T: Notch signaling controls germline stem cell niche formation in the Drosophila ovary. Development 2007;134:1071-1080.

45 Li LC, Peng Y, Liu YM, Wang LL, Wu XL: Gastric cancer cell growth and epithelial-mesenchymal transition are inhibited by gamma-secretase inhibitor DAPT. Oncol Lett 2014;7:2160-2164.

46 Xiao YG, Wang W, Gong D, Mao ZF: gamma-Secretase inhibitor DAPT attenuates intimal hyperplasia of vein grafts by inhibition of Notch1 signaling. Lab Invest 2014;94:654-662. 